\title{
The transformation of behaviour field studies
}

\author{
STUART A. ALTMANN* \& JEANNE ALTMANN* $¥ \ddagger$ \\ *Department of Ecology \& Evolutionary Biology, Princeton University \\ $\dagger$ Institute of Primate Research, National Museums of Kenya, Nairobi \\ ¥Department of Conservation Biology, Chicago Zoological Society, Brookfield \\ (Received 27 November 2002; \\ final acceptance 10 December 2002; MS. number: AAE-2)
}

\begin{abstract}
As areas of science mature, they pass through three, broadly overlapping stages of development, characterized respectively by description, explanation and synthesis. Field research on animal behaviour is making the transition from an area with a preponderance of purely descriptive studies to one that also includes the development and testing of verifiable hypotheses about the structure, causes and consequences of behaviour. We survey several reasons for this transformation of behaviour field studies and some of the major trends that characterize it, including: (1) patterns discerned in our cumulative knowledge of natural history; (2) increased support for behaviour field studies; (3) interfaces with related areas of science; (4) the development of observational sampling methods and other aspects of data sampling and analysis; (5) the development of models of behaviour's adaptive functions and life-history consequences; (6) long-term field sites that make possible complete life histories, increased attention to individual differences and intergenerational studies of behaviour; and (7) the development of techniques for remote tracking of animals and for noninvasive, hands-off sampling of a range of behavioural, physiological, genetic and environmental phenomena.
\end{abstract}

๑ 2003 Published by Elsevier Science Ltd on behalf of The Association for the Study of Animal Behaviour.

The study of animal behaviour in the wild is in the midst of a major transition. In the half century that Animal Behaviour has been published, field studies of behaviour have been moving from studies devoted almost entirely to descriptive natural history to a new stage that also includes development and testing of explanations for the causes and consequences of behaviour.

This transformation is not unique to animal behaviour. As each field of science matures, it passes through three, broadly overlapping stages of development, characterized respectively by a preponderance of description, explanation, or synthesis (cf. Wold 1956). In the initial descriptive approach, wonders of the natural world are revealed and patterns are discerned. Research is based on observation, description, correlation and classification, on assessing collective characteristics and demarcating classes of phenomena. Explanations, when offered at this initial state in a science's development, typically are proposed post hoc, and treatment of quantitative data, when available, rarely goes beyond descriptive statistics.

Correspondence: S. Altmann, Department of Ecology \& Evolutionary Biology, Princeton University, Princeton, NJ 08544, U.S.A. (email: salt@princeton.edu).
To this day, these are the characteristics of most field studies of behaviour.

As areas of science shift from pure description to description plus explanation, the focus shifts from asking only 'What?' to also asking 'Why?', and in some form or other the answer involves an element of causal inference. Tinbergen $(1951,1972)$ reminded us not only to describe behaviour but also to investigate its evolution, its functional consequences, and its causation, including external stimuli, internal mechanisms and development.

Although some explanations are proposed in the descriptive phase of research, those in the second phase characteristically include explanations sufficiently explicit to be tested against empirical research: they can be confirmed or falsified. A common perception is that models of behaviour will displace descriptive studies. This is a misconception. Research in every field of science contributes, within its domain, to answering the two, complementary questions: What is the nature of the world? and, Why is the world the way it is? Our attempts to answer these two questions are, respectively, description and explanation. The first without the second 
would be incomplete; the second could not exist without the first and is totally dependent on it for its veracity. As we shall document herein, the ongoing transformation of behaviour field studies involves major developments in both description and explanation.

In the final, synthetic stage, theories for disparate phenomena become special cases of more general theories.

Why is an accelerating transformation to testable explanations of naturalistic behaviour taking place at this time? We suggest several reasons. First, cumulative knowledge of natural history has repeatedly turned up patterns of behaviour that, along with their exceptions, cry out for explanation. For example, decades of field studies revealed that over $90 \%$ of bird species pair-bond 'monogamously' (Lack 1968). Why the consistency, and why the exceptions? In attempts to answer, several models of mating systems have been proposed and tested (e.g. Orians 1969; Altmann et al. 1977; Lenington 1980; Vehrencamp \& Bradbury 1984; Krebs \& Davies 1993).

Second, the study of naturalistic behaviour is surrounded by numerous relevant fields of science, many of which are relatively mature. In formulating and testing explanations of behaviour and even in deciding what phenomena to study, we shamelessly borrow from ecology, demography and selection theory, from molecular genetics, functional anatomy, physiology and nutritional sciences, and from the physical, mathematical and social sciences. Other sciences not only provide us with a wealth of concepts and techniques, they stimulate integration of behaviour with processes at other levels of organization, both higher and lower, including genetics, physiology and life-history processes.

Several developments in engineering and research design are now greatly facilitating the gathering and analysis of field data that previously could be obtained and analysed only laboriously or not at all. Recent conceptual and laboratory developments have also greatly facilitated important areas of research.

Finally, the transformation has been accelerated by increased support for field studies during the last half century, particularly in the decades after World War II. This support included increased research funding, development of long-term field sites, creation at various institutions of faculty positions earmarked for animal behaviour research, and increases in the numbers of scientific societies and journals devoted to naturalistic behaviour studies.

In what follows, we provide a sampling of this ongoing transformation of behaviour field studies. We emphasize several components of the transformation: (1) improved research methods, including those for research design, observational sampling and hypothesis testing; (2) improved tools for obtaining behavioural, ecological, genetic and physiological data; and finally, (3) descriptions and explanations of greater depth and breadth, relating naturalistic behaviour not only to ecology and physiology, but also to social structure, to demographic and life-history processes, and to population genetics.

In our own field research on primate behaviour, we have witnessed and participated in many aspects of the transformation of behaviour field research. Although here we draw inordinately on our own experiences for illustration, the changes we describe have been part of a much more widespread research trend, involving many people and, to varying degrees, many other taxa.

\section{ADAPTATIONS}

In recent years, the concept of adaptations has been changing in ways that are directly relevant to field studies of behaviour. Statements about the adaptive significance of traits, behavioural or otherwise, are being regarded not merely as plausible, post hoc explanations (Gould \& Lewontin 1979) but as testable hypotheses. The question underlying virtually all such testable hypotheses is this: Under given conditions, how would a well-adapted animal of this species behave? For behaviour, if the answer to this question is sufficiently explicit, then perforce we know, for any given pair of individuals, which one has behaviour that is better adapted to the circumstances. By an adaptation we mean a phenotypic variant that, within the environment considered, results in greater fitness relative to a specified set of competing variants (cf. West-Eberhard 1992; Reeve \& Sherman 1993).

Two separate but intimately related approaches are used to answer the above question about the adaptive significance of traits: by testing hypotheses relating to a trait's short-term (functional) consequences or by testing hypotheses relating to its long-term (fitness) consequences. Over the last half century, testable models relating to functional consequences of behaviour have been developed for various aspects of every major form of behaviour: territoriality, mate choice, parental care, foraging, and so on. Such models about functional consequences of behaviour predominate over studies that focus on fitness consequences of behaviour. This preponderance is well illustrated by research on foraging behaviour, the type of naturalistic behaviour that has produced the greatest number of explicit models and tests thereof (Pyke 1984; Stephens \& Krebs 1986; Kramer 2001).

At the heart of function-based models are the shortterm consequences of behaviour, variations of which can be ordered along an axis of better to worse. For example, because energy is vital to all biological activities, higherenergy diets are assumed to be better. In biology, the ultimate criterion of being better is biological fitness. For that reason, functional consequences are ordered better to worse by their (presumed) fitness consequences, and so are sometimes referred to as 'fitness surrogates'. Those individuals that behave so as to maximize the functional consequences of their behaviour (or minimize it, as appropriate) are assumed to be better off. (The more energy that is available for an animal's activities, the higher should be its fitness.)

However, the benefits that accrue from any behaviour also entail costs. There's No Such Thing As a Free Lunch (Friedman 1975). These costs are constraints or limiting factors (Liebig 1840; Blackman 1905; Shelford 1911): they limit the extent to which functional consequences of 
behaviour can be maximized (or minimized), and so, the function is said to be optimized. Optimality theory 'has revealed a richness and complexity in the patterns of foraging that could not have been imagined only a few decades ago' (Kramer 2001, page 232).

By themselves, function-based models are not able to address the possibility that our identification of a trait's functional consequences is incorrect, that the putative function may be a consequence that does not increase fitness. Yet, crucial in modelling adaptive behaviour is the correct identification of the model's 'currency', the functional consequence assumed to be optimized. For example, many foraging models use energy rate as the currency, whereas in some animals, protein maximization (White 1978) or foraging time minimization (Pyke et al. 1977) may be the primary factor limiting fitness. Even if an animal's fitness is energy limited, the rate at which energy-producing foods are consumed per minute of feeding may be the wrong currency, rather than, say, the amount of energy obtained per day, and maximizing the former does not in general maximize the latter (Altmann 1998).

In the second approach, the student of behaviour looks for a correlation between a trait (say, a form of behaviour) and biological fitness (as estimated by, say, lifetime reproductive success or other life-history components), in the hope of finding a consistent relationship, a 'fitness function', between the trait and fitness. This can lead, in turn, to studies of selection on such traits in natural populations (Endler 1986). However, not all fitness-correlated traits of an organism are interpretable as adaptations. Some may be mere by-products of other adaptations (Gould \& Lewontin 1979). To show that the trait in question actually results in greater fitness, we must ask, how does it do so?

An adaptation requires a rationale, a mechanism (Williams 1966). That brings us back to the question of whether we have correctly identified the functional significance of a trait. The most direct way to demonstrate that increased fitness is the result of a trait, not just a spurious correlate of it, is to confirm the two intermediate steps: to show that the trait has particular short-term, functional effects, and that these, in turn, limit fitness by altering life-history processes. Suppose that, by hypothesis, a form of behaviour or other trait has certain shortterm effects that supposedly affect fitness. Then, by taking advantage of intraspecific variability, one can test the behaviour's putative adaptive significance by asking whether those individuals whose behaviour has consequences that come closer to the hypothesized functional optimum are the ones whose fitness is higher, or at least (considering equivalent effects) not lower (Altmann 1991, 1998). Studies that combine quantitative data on all three (i.e. behaviour, its functions, and the fitnesslimiting effects of those functions) are labour intensive. However, they provide a richness of insights that cannot otherwise be obtained and, for that reason, we expect them to become more common.

Of growing importance in behaviour modelling are the use of dynamic optimization and game theory. This trend results from the ability of such models to incorporate context-dependent changes in behaviour, processes that are ignored in classical 'static' optimization models. In dynamic optimization (Houston \& McNamara 1999; Clark \& Mangel 2000), the animal's optimal choice of behaviour at any given time depends on its present condition and the future consequences of its available courses of action. Thus, these models deal with changing trade-offs in trajectories of decisions over time. For example, a great tit, Parus major, cannot defend its territory by singing and patrolling in the treetops while simultaneously foraging on the ground. Should a foraging great tit delay further feeding to shore up its territorial defence? That depends not only on the risk of territory intrusions but also on what the tit has eaten so far: a well-fed tit can afford to make the switch sooner (Ydenberg \& Houston 1986). Dynamic optimization models are currently being applied to diverse forms of behaviour (e.g. Pratt 1999; Weber et al. 1999; Kaesar et al. 2001; Pravosudov \& Lucas 2001; Webb et al. 2002).

Game theory (Maynard Smith 1982, 1984) and the related concept of evolutionarily stable strategies (Parker 1984) are particularly suitable for modelling the course of interactions between individuals who are responding to previous behaviour of individuals that are, in turn, responding to them. Consequently, game theory is particularly useful for modelling interactions between individuals that are adversaries or cooperators, or both. Currently, game theoretic models are being applied to a considerable variety of behaviour both in humans and in nonhuman animals (e.g. Noë 1990; Ball \& Parker 1998; Fryer et al. 1999; Giraldeau \& Caraco 2000; Godfray \& Johnstone 2000; Sirot 2000; Dodson \& Schwaab 2001; Renison et al. 2002; Richards 2002; Stevens \& Stephens 2002).

\section{RESEARCH DESIGN AND STATISTICAL ANALYSIS}

Here, we touch briefly on a few topics that are of particular relevance to the ongoing transformation of behaviour field studies.

\section{Sample Distribution Biases}

Field samples may be biased with regard to group size (Sharman \& Dunbar 1982), to particular behaviours, to age or sex classes, time of day, and so on. Some of these biases are unconscious. Some may result from preconceived ideas. Others inevitably result from field conditions. Consequently, when estimating actual values, the observed values need to be adjusted for differences in sample sizes (Question: Why do white sheep eat more than black ones? Answer: Because there are more of them!) In some situations, special techniques need to be developed, as we have done, for example, to calculate mean descent time of baboons from sleeping trees (Wagner \& Altmann 1973) and time spent in various quadrats of their home range (Altmann \& Altmann 1970).

\section{Rates of Behaviour}

A common question: how often does this behaviour occur? Because the answer usually depends on the span of 
time involved, many questions about frequencies of behaviour are actually questions about rates, that is, frequencies per unit of time. Rates can be estimated in four ways: from samples of the numbers of events in a fixed amount of time, of the amounts of time for a fixed number of events, of the number of events per unit of time where both time and number are random variables (e.g. bite rates during feeding bouts), and of the inverses of interevent intervals. Not surprisingly, each of these methods requires its own type of statistical analysis, but we do not know of any general survey of this topic. For the Poisson rate process, statistical methods are available (Cox \& Lewis 1966). However, a Poisson model is inappropriate for many types of behaviour, particularly ones that are durable (Rogosa \& Ghandour 1991). Recent statistical analyses of some other rate processes (e.g. Gardner et al. 1995; Susko et al. 2002) may be useful to students of behaviour.

Mathematical demography, including survival analysis, has produced some very useful tools for analysing behavioural field data. Here we consider two. In each case, the beginnings of intervals of behaviour (bouts) may be thought of as their births, the terminations, as their deaths.

\section{Bout Durations and Censored Data}

A common problem in field studies of behaviour is that the observer's view of the subjects is often interrupted by intervening foliage or other material, not because the animal is reacting to the observer but just because its movements inadvertently interpose view-blocking objects. Even on short-grass savannah, where we work, such interruptions are a problem; in tropical rainforests, they are often daunting. Consider an observer's focal sample data for a study on bout lengths of various activities. While many bouts may have been observed and timed from beginning to end, for others the actual duration is not known, because intervening material blocked the observer's view of the bouts' terminations or of their onsets. Fortunately, the statistical properties of such 'censored' data under various conditions have been the subject of numerous studies (e.g. Kaplan \& Meier 1958; Mantel 1966; Breslow 1970; Meier 1975). Statistical methods for estimating mean bout lengths and other distribution properties from censored data are now available and can be applied to field samples of behaviour (Bressers et al. 1991; Altmann 1998). Such techniques are now standard components of major statistical packages such as SAS/STAT (SAS Institute 1990).

\section{Event Distributions During Bouts}

Similarly, demographic analysis can be used to study the temporal distribution of events during intervals of behaviour. For example, in sampling patch foraging to test hypotheses about patterns of resource depression (Charnov et al. 1976), the consumption of each food item in a foraging bout is comparable to a birth during the interval's (the mother's) lifetime, and our task is that of estimating age-specific birth rates.

\section{Research Design}

All too often, students of naturalistic behaviour have returned from the field and discovered that their samples are too small to provide adequate answers to some of their questions, yet are unnecessarily large for others. Or samples, however large, may not be appropriate for the questions being asked. Fortunately, statistical research design is increasingly being used in planning and midcourse evaluation of observational field studies of behaviour and the literature on this topic is growing (e.g. Wold 1956; Cochran 1983; Manly et al. 1993; Martin \& Bateson 1993; Lehner 1996; Bart et al. 1999). A related development is a growing number of experiments on behaviour carried out in the field. Typically, the most illuminating of these abide by Tinbergen's admonition (1951) to observe the animals' full range of behaviour first, then experiment second, so that the most appropriate experiments can be designed. Outstanding examples include field experiments by Bachmann \& Kummer (1980), von Frisch's classical experiments on bees, and Tingergen's own research. A growing number of acoustical playback experiments are revealing a wide variety of social, perceptual and ecological phenomena (e.g. Cheney 1990; McComb et al. 1993, 2000; Cheney et al. 1995; Rendall et al. 1998; Mougeot \& Bretagnolle 2000; Semple \& McComb 2000; Fischer et al. 2001; Lewis et al. 2001; Wilson \& Vehrencamp 2001; Charrier et al. 2002).

\section{TOWARDS AN ANIMAL'S-EYE VIEW}

Animal behaviour research, like history as it was taught during the 1950s, has undergone a major transition from telling the story of a society by describing a few of the most conspicuous individuals performing their most spectacular acts, to a story of all individuals all of the time. In history class and textbooks, it was kings and queens, war and intrigue, and perhaps a dash of sex. For animal behaviour, it was often not much different, the emphasis in this case being on sex and aggression: warring ants, raping ducks, dominant male primates that were controlling, leading and protecting the masses while obtaining sexual access to the females.

In the 1970s and 1980s, a major shift began to occur that is still underway today. Many factors have contributed to the development of a much more comprehensive and realistic picture of animal behaviour, but three stand out: individual identification, systematic sampling methods and a growing recognition of the biases that result from ageism, sexism and their attendant terminology.

Not surprisingly perhaps, the drive to understand individual variability and, therefore, the effort to identify individuals, received particular impetus from researchers studying nonhuman primates, a mammalian order for which the importance of individuality is difficult to ignore. Although one might have expected individual recognition to be enthusiastically and rapidly embraced by any student of behavioural evolution, because intraspecific variability is so central to natural selection, study of individual primates and attention to individual 
differences was initially considered by some to be irrelevant or somewhat unscientific. Nevertheless, students investigating a range of research questions in a diversity of species from ants to swans to zebras soon developed observational or minimally intrusive identification techniques and were revealing hitherto unappreciated interindividual variability and individual plasticity in behaviour. (Even in social insects, 'much of the variability in behaviour not connected to caste and age polyethism must be attributable to individual differences in experience', Wilson 1971, page 165). The resulting explosion of possibilities for testing a range of evolutionary and mechanistic hypotheses will be ongoing for many decades to come.

Second, the rapid adoption of systematic sampling methods in field research and the associated concept of nonexperimental design also had a major role in the development of less biased and deeper studies of animal behaviour. A study of the relationships between observational sampling methods and the types of research questions for which each is appropriate (Altmann 1974) apparently filled a widespread need in behavioural research: that study has been cited more than 3000 times. See also Rogosa \& Ghandour (1991) for statistical properties of these sampling methods. Quantitative data on differences among individuals, at various life stages, and in a diversity of contexts became a reality when systematic sampling was combined with individual recognition and with the earlier insistence on rigour in ethograms. The promise of such data then demanded better testable hypotheses, more rigorous analyses, and appropriate statistical techniques. These needs remain, particularly in terms of statistical developments.

At the same time, collection and use of the data that could now be imagined under field conditions cried out for techniques of data collection that were faster and easier to analyse than is possible with the classical stopwatch combined with pencil and paper or tape recorder. At first, a few intrepid souls carried electronic data collection devices weighing $5 \mathrm{~kg}$ or more, ones that were vulnerable to dust, rain, dropping when one was chased by an elephant, and a range of other calamities. Only 20 years later, we take for granted hand-held electronic data loggers, in which, at the push of a button or two, one records an event and the time of its occurrence, all in computer-compatible form. At the end of the day, back at one's base camp, the data are transferred electronically into a computer, which can be powered by solar cells. Summary statistics can quickly be generated, so that one can check on, say, sample sizes. The arduous, timeconsuming and error-prone task of transcribing dictated data or computerizing paper-and-pencil data is eliminated.

A third major contributor to a less biased and more holistic picture of animal behaviour has to do with challenging the ageism and sexism that have been common in animal behaviour research and related fields of evolution and behavioural ecology (Hrdy \& Williams 1983) and that have resulted from choices of topics and measures, use of loaded and biased terminology, and ways of interpreting findings. This transition also began about 20-25 years ago with challenges to loaded and biased terminology (e.g. Gowaty 1982), with attention to selection during juvenile life stages (e.g. Hrdy \& Williams 1983) and with a shift in research focus from primarily males to both sexes and to the contrasting forces shaping the two sexes (e.g. Hrdy 1977, 1999; Altmann 1980, 1997; Fedigan 1982; Wasser 1983). Subsequently, research on sexual selection broadened from a primary focus on male competition and a secondary one on female choice to one that is finally beginning to consider the potential of male choice and female competition and that is extending the study of female choice through recognition of what Randy Thornhill (1983) termed 'cryptic female choice'. However important cryptic female choice turns out to be (Eberhard \& Cordero 1995; Eberhard 1996), it does now seem ludicrous that for so long, a female role was ignored in so-called sperm competition, even though such competition was usually being conducted within the bodies of females! The transformation is still underway, with both behavioural plasticity and ontogeny receiving muchdeserved renewed attention (e.g. West \& King 1988; King et al. 1996; West-Eberhard 2003).

\section{LIFE-HISTORY AND INTERGENERATIONAL STUDIES OF BEHAVIOUR}

As animal behaviour studies increasingly encompassed immature and ageing individuals, not just those in their reproductive prime, and females as well as males, consideration of complete life histories became possible (Merila \& Sheldon 2000; Grant \& Grant 2000). But, research on different life stages remains primarily that: the same individuals have only rarely been followed through time, even for short-lived species. Even when longitudinal data might have been obtained, as in long-term, bird-banding studies, the study of individual-based life histories lagged behind other topics. Perhaps inertia had a role in this delay. Perhaps, too, people have not appreciated the extent of covariances among life stages, cohort effects and the importance of early experience on adult functioning, although these have long been recognized within studies of human life histories and a focus on these issues is routine in human demography and sociology (Manton et al. 1992; Singer \& Ryff 1999; Seeman et al. 2002). Landmark longitudinal studies of human populations remain rare but significant. At the same time, quantitative genetic approaches (see Lande 1982; Arnold 1985; Halliday \& Arnold 1987; Arnold \& Duvall 1994) and matrix models (e.g. Stearns 1992; Caswell 2001) have been greatly developed and are being applied to studies of behavioural ecology and evolution (McDonald \& Caswell 1993; Alberts \& Altmann 2003).

None the less, challenges to obtaining appropriate lifetime demographic and behavioural data remain. One practical challenge is associated with some of the very life-history variants we seek to understand. The widespread presence of dispersal and the sex-biased nature of dispersal of many species often have posed seemingly insurmountable obstacles to obtaining lifetime behavioural and life-history data even in long-term field studies, hindrances circumvented in the species and sites 
for three particularly rich and well-known studies: of scrub-jays, Aphelocoma coerulescens (Woolfenden \& Fitzpatrick 1984), Darwin's finches (Geospizinae: Grant \& Grant, 1989, 2002) and red deer, Cervus elaphus (CluttonBrock et al. 1982; Kruuk et al. 2000).

\section{TECHNIQUES FOR REMOTE AND INDIRECT BEHAVIOUR MONITORING}

Advances in remote tracking of radiotagged animals are beginning to contribute immeasurably, both in enabling one to locate animals that otherwise would have been very difficult or impossible to find and also in providing indirect evidence of behaviour that occurs in our absence. Examples include automated tracking of deer by Yagi antennas; studies of marine animals for whom attached measuring devices record and store a month of data on location, level of activity and physiological information; radiocollared elephants or long-distance migrating birds whose physiology is monitored by radiotracking from vehicles, from airplanes, or now by satellites (Bevan et al. 1994; Guyton et al. 1995; Block et al. 1998, 2001; Lutcavage et al. 1999; Butler et al. 2000; Boehlert et al. 2001; Beck et al. 2002; Wikelski \& Cochran, in press).

Within this decade, we are likely to have far greater capacity for remote tracking. For example, in a project dubbed Zebranet (Schultz 2002), wild animals will carry radiotags that can 'talk' to each other. Thus, when two tagged animals interact or are near each other, the logged information from each will be transferred to the other, and as a tagged lion eats a tagged zebra, all the stored information about the activities of the prey and all other tagged zebras that it has been near will be transferred to the lion's tag! On Barro Colorado Island, Panama, arrays of directional antennas on seven towers will, by next year, enable radiotagged animals to be located almost anywhere on the island (Larkin et al. 1996; Wikelski 2002) and the ICARUS initiative (ICARUS 2002) will make possible the tracking of intercontinental songbird migrations.

Similarly, in the tradition of Muybridge's (1887) early trip-camera studies of locomotion, animal-activated sound recorders and still or video cameras have been used to great advantage in recent decades to record behaviour in the absence of an observer (Frith et al. 1996), revealing unknown or poorly documented aspects of behaviour and enabling hypothesis testing where only rare case studies would otherwise be available.

Analysis of isotopes in faeces can reveal the trophic levels of animals and the proportions of browse versus graze that herbivores consume (Tieszen 1991). Microscopic analysis of plant residues in herbivore faeces can, laboriously, reveal their diet (Stewart \& Stewart 1970).

Of course, technical developments have also benefited studies of observable animals, greatly improving the quality and scope of field data. Locations, once recorded on laboriously drawn maps, can now be obtained with submetre accuracy almost anywhere in the world from satellite information by way of hand-held instruments, using the Geographic Positioning System (GPS). The speed of a running or flying animal can be measured precisely by instruments that use Doppler-effect phase shift (Tong 2002). For measuring distances, hand-held, laser-based range finders have an accuracy of one part per thousand. Some come with a built-in, electronic compass. One can foresee an offshoot of these in which the laser beam is pointed in turn at each animal in a group, and the instrument records the group's geometry, that is, the spatial deployment of the individuals relative to each other. Although precision heat-sensing devices are not yet within the price range for most field use, West \& Packer (2002) used a borrowed one to great advantage in a study of body heat of lions that differed in mane colour.

For recording animal sounds, parabolic reflectors, which need to be large for sounds of low frequencies or low intensities, can be replaced by 'shotgun' microphones, which are far more compact and thus less intrusive as well as more manageable. For many years, portable Nagra recorders have made possible highquality field recordings of animal sounds, and sound spectrographs have provided the means of analysing their temporal, frequency and amplitude components. Repositories and distributors such as the MacCauley Library of Natural History Sounds at Cornell have greatly expanded and also increasingly serve as a source of information about equipment and software for acoustics analysis. Like other research areas, field studies benefit from the Worldwide Web's ability to facilitate locating, obtaining and distributing information.

Perhaps the one major piece of field equipment that has had only minor improvements in the last half century is the field vehicle: still too uncomfortable, too fragile and too expensive.

\section{TECHNIQUES FOR BEHAVIOUR-FRIENDLY PHYSIOLOGICAL STUDIES}

Just as remote tracking and recording provide clues and indirect measures or traces of behaviour that we are unable to observe directly, other methodological developments are enabling the testing of hypotheses about causes and consequences of behaviour in undisturbed natural populations, hypothesis testing that was previously impossible for many species, particularly without intolerable disturbance. One such area is field measurement of physiological variables, including indicators of body condition (Knott 1998), energy expenditure (Schoeller 1988) and steroid concentrations (Sapolsky 1993; Soma \& Wingfield, 2001; Wingfield et al. 2001). The landmark physiological studies, such as those of Sapolsky and Wingfield, required blood sampling, which is still needed for many physiological variables (e.g. energy expenditure and total body fat, measured through isotope-labelled water; Schoeller 1988).

For some species or for repeated sampling of individuals, trapping or darting to obtain blood samples is not always desirable, feasible, or in some cases legal. Thanks to emerging methods for completely noninvasive handsoff sampling, through use of urine or faeces, we can obtain a greatly enhanced window into an individual's physiology throughout its lifetime. For some species and 
habitats, urine sampling is possible, increasing the range of hormones that can be measured (Andelman et al. 1985; van Schaik et al. 1991; Robbins \& Czekala 1997). For others, only faeces are feasible, thereby restricting the range to steroid hormones but enhancing the ability to obtain measures that are integrated over time (Brockman \& Whitten 1996; Whitten \& Russell 1996; Savage et al. 1997; Whitten et al. 1998). Initial studies using urine or faeces have included a range of mammals, such as mongooses, wild dogs, wolves, elephants and primates (Monfort et al. 1998; Creel et al. 2002 and references above). As validation extends to more species, conditions and hormones, the potential is enormous. Noninvasive hormone sampling has thus far been implemented primarily in mammal species. However, recent documentation of variability among avian species in timing of the stress response to capture (e.g. Romero \& Romero 2002) may be one of several factors that will favour application of these techniques to avian and other taxa.

\section{GENETIC RELATEDNESS AND BEHAVIOUR}

Many questions about behavioural ecology and adaptation require measures of fitness and of genetic relatedness among individuals. A few decades ago, relatedness within natural populations was deduced almost entirely from observations of broad categories of social behaviour. For example, avian social pair bonding and offspring care by an adult male and female were assumed to indicate monogamy. This situation best represents the revolution initiated by numerous recent advances in molecular genetic techniques and applications (e.g. PCR, microsatellite developments, and the Human Genome Project). When various 'monogamous' species were suddenly found to be not so (e.g. Gowaty \& Karlin 1984; Westneat 1987; Gowaty \& Bridges 1991), some at first doubted the genetic results. However, with confirmation and with similar findings in many species (Birkhead \& Møller 1992), the pendulum soon swung the other way, with many questioning any ability to predict parentage from behaviour! The problem, of course, was not with behaviour but with the level of behaviour that was being recorded by researchers. The nestling's true father must have mated with the mother, but observers did not observe these matings.

If anything, the genetic results of the past decade have reminded us that behaviour must be taken more seriously, not less, and studied with rigour. We cannot count on gross measures several steps removed. For example, even in a 'promiscuous' (more accurately, polygynandrous) species like the savannah baboon, Papio cynocephalus, that we study, we identified conditions in which not only observed mating behaviour but also male dominance status were excellent predictors of paternity distribution (Altmann et al. 1996). However, we also postulated the conditions under which such a dominance-based 'queuing' model of mating behaviour and paternity would not hold. This hypothesis has received support in recent tests (Alberts et al. 2003); genetic investigations are underway in Alberts' laboratory.
One of the results of the growing number of parentage studies in wild populations is the realization that not only do some offspring have different parents than assumed by observers (and perhaps by the putative parents), but also that females are mating with more than one male and are even seeking these additional matings, the final blow to the Victorian and male-oriented remnants of an earlier era of animal behaviour studies. Therefore, not only should we not assume that pair-bonded female birds are being 'raped' when they mate with a nonmate, but we are also obliged to recognize that 'rape' may occur within pair bonds, and perhaps, what was previously called 'rape' outside a pair bond is an instance of 'adultery', of paternity confusion, or some other aspect of females' control over their own reproduction (Smuts \& Smuts 1993; Gowaty 1994, 1997). We are only beginning to elucidate the many ways that females and males affect their potential for offspring production (Hrdy 1999).

In addition, evolutionary geneticists are finally joining with behavioural ecologists in acknowledging the need for studies that cross generations, not stopping with mates obtained or even with zygotes produced. As evolutionary models and empirical research increasingly include topics such as parental effects (alas, termed 'maternal effects') and as developmental biology at its best begins to elucidate the transformation of genotype to phenotype at all life stages and within the full range of potential contexts, we will come full circle in focusing on the whole individual, in its social and ecological contexts and throughout its life, the subject that originally captured the attention of so many of us. We can now do so with the potential to dig much deeper than we could previously and in the process we shall find even more exciting uses for the emerging technologies than the particular tasks for which they were developed. We can already provide an example. Genetic analysis can be carried out not only on blood, muscle or other tissue, as in the earlier studies cited above, it can also be done on hair or faeces, which can be obtained from undisturbed, wild, but identified individuals (Höss et al. 1992; Inoue \& Takenaka 1993; Sugiyama et al. 1993; Morin et al. 1994; Kohn \& Wayne 1997). This makes possible both determination of genetic relatedness and also the study of population genetics and its relation to group processes without compromising behaviour-sensitive investigations (Melnick 1987; Melnick \& Goldstein 1988; Morin et al. 1994; Alberts 1999; Constable et al. 2001; Vigilant et al. 2001; Smith et al., in press).

\section{CAVEAT}

Recent and continuing advances in concepts and methods are beginning to transform field research in ways that could hardly be imagined 50 years ago when this journal began publication. We are able to study not only the behaviour of animals in the wild, but also, its causes and its consequences. That does not mean that we can do such studies with just our binoculars, a pair of boots, and a beaten-up field vehicle, although we still need these. Many of the tools of modern research on naturalistic behaviour are costly, for both field work and 
the related laboratory investigation: genotyping and sequencing, sound recording and analysis equipment, physiological assays, and so on. A major and essential challenge to our community for assuring the health of future decades of animal behaviour research will be to convince the sources of funding that such research requires the budgets of modern biology to achieve both the potential of animal behaviour research and of the reductionist fields to which, in exchange for their tools and approaches, it can contribute valuable insights into the significance of lower-level processes. If we keep our eyes on our animals, if we retain what Helen Fox Keller (1983) termed 'a feeling for the organism', animal behaviour will never be a field that is tool-driven, but we must become a field that is tool-enabled if we are to answer many of the central questions of behavioural biology.

\section{Acknowledgments}

Our thanks to Susan Alberts, Jeff Lucas, Dan Rubenstein, Jeff Walters and an anonymous referee for their comments on the manuscript, and to Jessica Lynch, Kerri Smith and Martin Wikelski, who provided relevant references. We gratefully acknowledge the many animal behaviourists who, both formally and informally, have helped shape our rich experiences studying naturalistic behaviour, and the students, collaborators and animals with whom so many wondrous research experiences have been shared over several decades. Jeanne Altmann appreciates research support from the National Science Foundation (IBN 9985910).

\section{References}

Alberts, S. C. 1999. Paternal kin discrimination in wild baboons. Proceedings of the Royal Society of London, Series B, 266, 15011506.

Alberts, S. C. \& Altmann, J. 2003. Matrix models for primate life history analysis. In: Primate Life History and Socioecology (Ed. by P. Kappeler \& M. E. Pereira), pp. 66-102. Chicago: University of Chicago Press.

Alberts, S. C., Watts, H. E. \& Altmann, J. 2003. Queuing and queue-jumping: long term patterns of reproductive skew among male savannah baboons. Animal Behaviour.

Altmann, J. 1974. Observational study of behavior: sampling methods. Behaviour, 49, 227-265.

Altmann, J. 1980. Baboon Mothers and Infants. Cambridge, Massachusetts: Harvard University Press (Revised and reprinted 2001, Chicago: Chicago University Press).

Altmann, J. 1997. Mate choice and intrasexual reproductive competition: contributions to reproduction that go beyond acquiring more mates. In: Feminism and Evolutionary Biology: Boundaries, Intersections and Frontiers (Ed. by P. A. Gowaty), pp. 320-333. New York: Chapman \& Hall.

Altmann, J., Alberts, S. C., Haines, S. A., Dubach, J., Muruthi, P., Coote, T., Geffen, E., Cheesman, D. J., Mututua, R. S., Saiyalel, S. N., Wayne, R. K., Lacy, R. C. \& Bruford, M. W. 1996. Behaviour predicts genetic structure in a wild primate group. Proceedings of the National Academy of Sciences, U.S.A., 93, 57975801.
Altmann, S. A. 1991. Diets of yearling primates (Papio cynocephalus) predict lifetime fitness. Proceedings of the National Academy of Sciences, U.S.A., 88, 420-423.

Altmann, S. A. 1998. Foraging for Survival: Yearling Baboons in Africa. Chicago: University of Chicago Press.

Altmann, S. A. \& Altmann, J. 1970. Baboon Ecology: African Field Research. Chicago: University of Chicago Press.

Altmann, S. A., Wagner, S. S. \& Lenington, S. 1977. Two models for the evolution of polygyny. Behavioral Ecology and Sociobiology, 2, 397-410.

Andelman, S. J., Else, J. G., Hearn, J. P. \& Hodges, J. K. 1985. The non-invasive monitoring of reproductive events in wild vervet monkeys (Cercopithecus aethiops) using urinary pregnanediol3-alpha-glucuronide and its correlation with behavioural observations. Journal of Zoology, A205, 467-477.

Arnold, S. J. 1985. Quantitative genetic models of sexual selection. Experientia, 41, 1296-1310.

Arnold, S. J. \& Duvall, D. 1994. Animal mating systems: a synthesis based on selection theory. American Naturalist, 143, 317-348.

Bachmann, C. \& Kummer, H. 1980. Male assessment of female choice in hamadryas baboons. Behavioral Ecology and Sociobiology, 6, 315-321.

Ball, M. A. \& Parker, G. A. 1998. Sperm competition games: a general approach to risk assessment. Journal of Theoretical Biology, 194, 251-262.

Bart, J., Fligner, M. A. \& Notz, W. I. 1999. Sampling and Statistical Methods for Behavioural Ecologists. Cambridge: Cambridge University Press.

Beck, C. A., McMillan, J. I. \& Bowen, W. D. 2002. An algorithm to improve geolocation positions using sea surface temperature and diving depth. Marine Mammal Science, 18, 940-951.

Bevan, R. M., Woakes, A. J., Butler, P. J. \& Boyd, I. L. 1994. The use of heart rate to estimate oxygen consumption of free-ranging black-browed albatrosses Diomedea melanophrys. Journal of Experimental Biology, 193, 119-137.

Birkhead, T. R. \& Møller, A. P. 1992. Sperm Competition in Birds: Evolutionary Causes and Consequences. London: Academic Press.

Blackman, F. F. 1905. Optima and limiting factors. Annuals of Botany, 19, 281-295.

Block, B. A., Dewar, H., Farwell, C. \& Prince, E. D. 1998. A new satellite technology for tracking the movements of Atlantic bluefin tuna. Proceedings of the National Academy of Sciences, U.S.A., 95, 9384-939.

Block, B. A., Dewar, H., Blackwell, S. B., Williams, T. D., Prince, E. D., Farwell, C. J., Boustany, A., Teo, S. L. H., Seitz, A., Walli, A. \& Fudge, D. 2001. Migratory movements, depth preferences, and thermal biology of Atlantic bluefin tuna. Nature, 298, 1310-1314.

Boehlert, G. W., Costa, D. P., Crocker, D. E., Green, P., O'Brian, T., Levitus, S. \& Le Boeuf, B. J. 2001. Autonomous pinniped environmental samplers: using instrumented animals as oceanographic data collectors. Journal of Atmospheric and Oceanic Technology, 18, 1882-1893.

Breslow, N. 1970. A generalized Kruskal-Wallis test for comparing K samples subject to unequal pattern of censorship. Biometrika, 57, 579-594.

Bressers, M., Meelis, E., Haccou, P. \& Kruk, M. 1991. When did it really start or stop: the impact of censored observations on the analysis of duration. Behavioral Processes, 23, 1-20.

Brockman, D. K. \& Whitten, P. L. 1996. Reproduction in freeranging Propithecus verreauxi: estrus and the relationship between multiple partner matings and fertilization. American Journal of Physical Anthropology, 100, 57-69.

Butler, P. J., Woakes, A. J., Bevan, R. M. \& Stephenson, R. 2000. Heart rate and rate of oxygen consumption during flight of the barnacle goose, Branta leucopsis. Comparative Biochemistry and Physiology, Part A, 126, 379-385. 
Caswell, H. 2001. Matrix Population Models: Construction, Analysis and Interpretation. 2nd edn. Sunderland, Massachusetts: Sinauer.

Charnov, E. L., Orians, G. H. \& Hyatt, K. 1976. Ecological implications of resource depression. American Naturalist, 110, 247-259.

Charrier, I., Mathevon, N. \& Jouventin, P. 2002. How does a fur seal mother recognize the voice of her pup? An experimental study of Arctocephalus tropicalis. Journal of Experimental Biology, 205, 603-612.

Cheney, D. L. 1990. How Monkeys See the World: Inside the Mind of Another Species. Chicago: Chicago University Press.

Cheney, D. L., Seyfarth, R. M. \& Silk, J. B. 1995. The role of grunts in reconciling opponents and facilitating interactions among adult female baboons. Animal Behaviour, 50, 249-257.

Clark, C. W. \& Mangel, M. 2000. Dynamic State Variables in Ecology: Methods and Applications. New York: Oxford University Press.

Clutton-Brock, T. H., Guinness, F. E. \& Albon, S. D. 1982. Red Deer: Behavior and Ecology of Two Sexes. Chicago: University of Chicago Press.

Cochran, W. G. 1983. Planning and Analysis of Observational Studies. Chichester: J. Wiley.

Constable, J., Ashley, M., Goodall J. \& Pusey, A. 2001. Noninvasive paternity assignment in Gombe chimpanzees. Molecular Ecology, 10, 1279-1300.

Cox, D. R. \& Lewis, P. A. W. 1966. The Statistical Analysis of Series of Events. London: Methuen.

Creel, S., Fox, J. E., Hardy, A., Sands, J., Garrott, B. \& Peterson, R. O. 2002. Snowmobile activity and glucocorticoid stress responses in wolves and elk. Conservation Biology, 16, 809-814.

Dodson, G. N. \& Schwaab, A. T. 2001. Body size, leg autonomy, and prior experience as factors in the fighting success of male crab spiders, Misumenoides formosipes. Journal of Insect Behavior, 14, 841-855.

Eberhard, W. G. 1996. Female Control: Sexual Selection by Cryptic Female Choice. Princeton, New Jersey: Princeton University Press.

Eberhard, W. G. \& Cordero, C. 1995. Sexual selection by cryptic female choice on male seminal products: a new bridge between sexual selection and reproductive physiology. Trends in Ecology and Evolution, 10, 493-496.

Endler, J. 1986. Natural Selection in the Wild. Princeton, New Jersey: Princeton University Press.

Fedigan, L. M. 1982. Primate Paradigms: Sex Roles and Social Bonds. Montréal: Eden Press. (Revised and reprinted 1992, Chicago: University of Chicago Press.)

Fischer, J., Metz, M., Cheney, D. L. \& Seyfarth, R. M. 2001. Baboon responses to graded bark variants. Animal Behaviour, 61, 925-931.

Friedman, M. 1975. There's No Such Thing As a Free Lunch. LaSalle, Illinois: Open Court.

Frith, C. B., Borgia, G. \& Frith, D. W. 1996. Courts and courtship behaviour of Archbold's bowerbird (Archboldia papuensis) in Papua New Guinea. Ibis, 138, 204-211.

Fryer, T., Cannings, C. \& Vickers, G. T. 1999. Sperm competition I: basic model, ESS and dynamics. Journal of Theoretical Biology, 196, 81-100.

Gardner, W. E., Mulvey, E. P. \& Shaw, E. C. 1995. Regressionanalyses of counts and rates: poisson, overdispersed poisson, and negative binomial models. Psychological Bulletin, 118, 392404.

Giraldeau, L.-A. \& Caraco, T. 2000. Social Foraging Theory. Princeton, New Jersey: Princeton University Press.

Godfray, H. C. J. \& Johnstone, R. A. 2000. Begging and bleating: the evolution of parent-offspring signaling. Philosophical Transactions of the Royal Society of London, Series B, 355, 15811591.

Gould, S. J. \& Lewontin, R. C. 1979. The spandrels of San Marco and the Panglosian paradigm: a critique of the adaptationist programme. Proceedings of the Royal Society of London, Series $B_{1}$ 205, 581-598.

Gowaty, P. A. 1982. Sexual terms in sociobiology: emotionally evocative and, paradoxically, jargon. Animal Behaviour, 30, 630631.

Gowaty, P. A. 1994. Architects of sperm competition. Trends in Ecology and Evolution, 9, 160-162.

Gowaty, P. A. 1997. Feminism and Evolutionary Biology: Boundaries, Intersections, and Frontiers. New York: Chapman \& Hall.

Gowaty, P. A. \& Bridges, W. 1991. Nestbox availability affects extra-pair fertilization and conspecific nest parasitism in eastern bluebirds, Sialia sialis. Animal Behaviour, 41, 661-675.

Gowaty, P. A. \& Karlin, A. A. 1984. Multiple maternity and paternity in single broods of apparently monogamous eastern bluebirds (Sialia sialis). Behavioral Ecology and Sociobiology, 15, 91-95.

Grant, B. \& Grant, P. R. 1989. Evolutionary Dynamics of a Natural Population: the Large Cactus Finch of the Galápagos. Chicago: Chicago University Press.

Grant, P. R. \& Grant, B. R. 2000. Non-random fitness variation in two populations of Darwin's finches. Proceeding of the Royal Society of London, Series B, 267, 131-138.

Grant, P. R. \& Grant, B. R. 2002. Unpredictable evolution in a 30-year study of Darwin's finches. Science, 296, 707-711.

Guyton, G. P., Stanek, K. S., Schneider, R. C., Hochachka, P. W., Hurford, W. E., Zapol, D. G., Liggins, G. C. \& Zapol, W. M. 1995. Myoglobin saturation in free-diving Weddell seals. Journal of Applied Physiology, 79, 1148-1155.

Halliday, T. \& Arnold, S. J. 1987. Multiple mating by females: a perspective from quantitative genetics. Animal Behaviour, 35, 939-941

Höss, M., Kohn, M. \& Paabo, S. 1992. Excrement analysis by PCR. Nature, 359, 199.

Houston, A. I. \& McNamara, J. M. 1999. Models of Adaptive Behaviour: an Approach Based on State. Cambridge: Cambridge University Press.

Hrdy, S. B. 1977. The Langurs of Abu: Female and Male Strategies of Reproduction. Cambridge, Massachusetts: Harvard University Press.

Hrdy, S. B. 1999. Mother Nature: a History of Mothers, Infants and Natural Selection. New York: Pantheon Books.

Hrdy, S. B. \& Williams, G. C. 1983. Behavioral biology and the double standard. In: Social Behavior of Female Vertebrates (Ed. by S. K. Wasser), pp. 3-17. New York: Academic Press.

ICARUS 2002. www.princeton.edu/tracking/ICARUS website/ index.htm.

Inoue, M. \& Takenaka, O. 1993. Japanese macaque microsatellite PCR primers for paternity testing. Primates, 34, 37-45.

Kaesar, T., Ney-Nifle, M., Mangel, M. \& Swezey, S. 2001. Early oviposition experience affects patch residence time in a foraging parasitoid. Entomologia Experimentalis et Applicata, 98, 123132.

Kaplan, E. L. \& Meier, P. 1958. Non-parametric estimation from incomplete observations. Journal of the American Statistical Association, 53, 457-481.

Keller, H. F. 1983. A Feeling for the Organism: the Life Work of Barbara McClintock. New York: W. H. Freeman.

King, A. P., West, M. J. \& Freeberg, T. M. 1996. Social experience affects the process and outcome of vocal ontogeny in two populations of cowbirds. Journal of Comparative Psychology, 110, 276-285

Knott, C. D. 1998. Changes in orangutan caloric intake, energy balance, and ketones in response to fluctuating fruit availability. International Journal of Primatology, 19, 1061-1079.

Kohn, M. H. \& Wayne, R. K. 1997. Facts from feces revisited. Trends in Ecology and Evolution, 12, 223-227. 
Kramer, D. L. 2001. Foraging behavior. In: Evolutionary Ecology (Ed. by C. W. Fox, D. A. Roff \& D. J. Fairbairn), pp. 232-246. Oxford: Oxford University Press.

Krebs, J. R. \& Davies, N. B. 1993. An Introduction to Behavioural Ecology. 3rd edn. Oxford: Blackwell Scientific.

Kruuk, L. E. B., Clutton-Brock, T. H., Slate, J., Pemberton, J. M., Brotherstone, S. \& Guinness, F. E. 2000. Heritability of fitness in a wild mammal population. Proceedings of the National Academy of Sciences, U.S.A., 97, 698-703.

Lack, D. 1968. Ecological Adaptations for Breeding in Birds. London: Methuen.

Lande, R. 1982. A quantitative genetic theory of life history evolution. Ecology, 63, 607-615.

Larkin, R. P., Raim, A. \& Diehl, R. H. 1996. Performance of a nonrotating direction-finder for automatic radio tracking. Journal of Field Ornithology, 67, 59-71.

Lehner, P. N. 1996. Handbook of Ethological Methods. 2nd edn. New York: Cambridge University Press.

Lenington, S. G. 1980. Female choice and polygyny in red-winged blackbirds. Animal Behaviour, 28, 347-361.

Lewis, E. R., Narins, P. M., Cortopassi, K. A., Yamada, W. M., Poinar, E. H., Moore, S. W. \& Yu, X. L. 2001. Do male white-lipped frogs use seismic signals for intraspecific communications? American Zoologist, 41, 1185-1199.

Liebig, J. 1840. Chemistry in Its Application to Agriculture and Physiology. London: Taylor \& Walton.

Lutcavage, M. W., Brill, R. W., Skomal, G. B., Chase, B. C. \& Howey, P. C. 1999. Results of pop-up satellite tagging of spawning size class fish in the Gulf of Mexico: do North Atlantic bluefin tuna spawn in the mid-Atlantic? Canadian Journal of Fisheries and Aquatic Sciences, 56, 173-177.

McComb, K., Moss, C., Sayialel, S. \& Baker, L. 2000. Unusually extensive networks of vocal recognition in African elephants. Animal Behaviour, 59, 1103-1109.

McComb, K., Pusey, A., Packer, C. \& Grinnell, J. 1993. Female lions can identify potentially infanticidal males from their roars. Proceedings of the Royal Society of London, Series B, 252, 59-64.

McDonald, D. B. \& Caswell, H. 1993. Matrix methods in avian demography. Current Ornithology, 10, 139-185.

Manly, B. F. J., McDonald, L. L. \& Thomas, D. L. 1993. Resource Selection by Animals: Statistical Design and Analysis of Field Studies. London: Chapman \& Hall.

Mantel, N. 1966. Evaluation of survival data and two new rank order statistics arising in its consideration. Cancer Chemotherapy Report, 50, 163-170.

Manton, K. G., Stallard, E. \& Singer, B. 1992. Projecting the future size and health-status of the United-States elderly population. International Journal of Forecasting, 8, 433-458.

Martin, P. \& Bateson, P. 1993. Measuring Behaviour: an Introductory Guide. 2nd edn. Cambridge: Cambridge University Press.

Maynard Smith, J. 1982. Evolution and the Theory of Games. Cambridge: Cambridge University Press.

Maynard Smith, J. 1984. Game theory and the evolution of behaviour. Behavior and Brain Sciences, 7, 95-125.

Meier, P. 1975. Estimation of a distribution function from incomplete observations. In: Perspectives in Probability and Statistics (Ed. by J. Gani), pp. 67-87. Sheffield: Applied Probability Trust.

Melnick, D. J. 1987. The genetic consequences of primate social organization: a review of macaques, baboons and vervet monkeys. Genetica, 73, 117-135.

Melnick, D. J. \& Goldstein, S. J. 1988. Are primate social groups random collections of a population's genotypes? American Journal of Physical Anthropology, 75, 250.

Merila, J. \& Sheldon, B. C. 2000. Lifetime reproductive success and heritability in nature. American Naturalist, 155, 301-310.

Monfort, S. L., Mashburn, K. L., Brewer, B. A. \& Creel, S. R. 1998. Evaluating adrenal activity in African wild dogs (Lycaon pictus) by fecal corticosteroid analysis. Journal of Zoo and Wildlife Medicine, 29, 139-133.

Morin, P. A., Moore, J. J., Chakraborty, R., Jin, L., Goodall, J. \& Woodruff, D. S. 1994. Kin selection, social structure, gene flow, and the evolution of chimpanzees. Science, 265, 1193-1201.

Mougeot, F. \& Bretagnolle, V. 2000. Predation as a cost of sexual communication in nocturnal seabirds: an experimental approach using acoustic signals. Animal Behaviour, 60, 647-656.

Muybridge, E. 1887. Animal Locomotion: an Electro-photographic Investigation of Consecutive Phases of Animal Movement, 1872 1885. Philadelphia: University of Pennsylvania.

Noë, R. 1990. A veto game played by baboons: a challenge to the use of the prisoners-dilemma as a paradigm for reciprocity and cooperation. Animal Behaviour, 39, 78-90.

Orians, G. H. 1969. On the evolution of mating systems in birds and mammals. American Naturalist, 103, 589-603.

Parker, G. A. 1984. Evolutionarily stable strategies. In: Behavioural Ecology: an Evolutionary Approach. 2nd edn (Ed. by J. R. Krebs \& N. B. Davies), pp. 3-61. Sunderland, Massachusetts: Sinauer.

Pratt, S. C. 1999. Optimal timing of comb construction by honeybee (Apis mellifera) colonies: a dynamic programming model and experimental tests. Behavioral Ecology and Sociobiology, 46, 30-42.

Pravosudov, V. V. \& Lucas, J. R. 2001. Daily patterns of energy storage in food-catching birds under variable daily predation risk: a dynamic state variable model. Behavioral Ecology and Sociobiology, 50, 239-250.

Pyke, G. H. 1984. Optimal foraging theory: a critical review. Annual Review of Ecology and Systematics, 15, 523-575.

Pyke, G. H., Pulliam, H. R. \& Charnov, E. L. 1977. Optimal foraging: a selective review of theory and tests. Quarterly Review of Biology, 52, 137-154.

Reeve, H. K. \& Sherman, P. W. 1993. Adaptation and the goals of evolutionary research. Quarterly Review of Biology, 68, 1-32.

Rendall, D., Owren, M. J. \& Rodman, P. S. 1998. The role of vocal tract filtering in identity cueing in rhesus monkey (Macaca mulatta) vocalizations. Journal of the Acoustical Society of America, 103, 602-614.

Renison, D., Boersma, D. \& Martella, M. B. 2002. Winning and losing: causes for variability in outcome of fights in male Magellanic penguins. Behavioral Ecology, 13, 462-466.

Richards, S. A. 2002. Temporal partitioning and aggression among foragers: modeling the effects of stochasticity and individual state. Behavioral Ecology, 13, 427-438.

Robbins, M. M. \& Czekala, N. M. 1997. A preliminary investigation of urinary testosterone and cortisol levels in wild male mountain gorillas. American Journal of Primatology, 43, 51-64.

Rogosa, D. \& Ghandour, G. 1991. Statistical models for behavioral observation. In: Journal of Educational Statistics. Special Issue: Behavioral Observations (Ed. by R. K. Tsutakawa), pp. 157-252. Washington, D.C.: American Educational Research Association.

Romero, L. M. \& Romero, R. C. 2002. Corticosterone responses in wild birds: the importance of rapid initial sampling. Condor, 104, 129-135.

Sapolsky, R. 1993. Endocrinology alfresco: psychoendocrine studies of wild baboons. Recent Progress in Hormone Research, 48, 437-468.

SAS Institute. 1999. SAS/STAT User's Guide. Version 9. Cary, North Carolina: SAS Institute.

Savage, A., Shideler, S. E., Soto, L. H., Causado, J., Giraldo, L. H., Lasley, B. L. \& Snowdon, C. T. 1997. Reproductive events of wild cotton-top tamarins (Saguinus oedipus) in Colombia. American Journal of Primatology, 43, 329-337.

Schoeller, D. A. 1988. Measurement of energy expenditure in free-living humans by doubly labeled water. Journal of Nutrition, 118, 1278-1289.

Schultz, S. 2002. Engineers and biologists design wireless devices to unlock secrets of animal kingdom. Princeton Weekly Bulletin, 92, 9. http://www. princeton.edu/pr/pwb/02/1111/. 
Seeman, T. E., Singer, B. H., Ryff, C. D., Love, G. D. \& LevyStorms, L. 2002. Social relationships, gender and allostatic loads across two age cohorts. Psychosomatic Medicine, 64, 395-406.

Semple, S. \& McComb, K. 2000. Perception of female reproductive state from vocal cues in a mammal species. Proceedings of the Royal Society of London, Series B, 267, 707-712.

Sharman, M. \& Dunbar, R. I. M. 1982. Observer bias in selection of study group in baboon field studies. Primates, 23, 567-573.

Shelford, V. E. 1911. Physiological animal geography. Journal of Morphology, 22, 551-618.

Singer, B. \& Ryff, C. D. 1999. Hierarchies of life histories and associated health risks. Annals of the New York Academy of Sciences, 896, 96-115.

Sirot, E. 2000. An evolutionarily stable strategy for aggressiveness in feeding groups. Behavioral Ecology, 11, 351-356.

Smith, K., Alberts, S. C. \& Altmann, J. In press. Wild female baboons bias their social behaviour towards paternal half-sisters. Proceedings of the Royal Society of London, Series B, 270. A (also at www.princeton.edu/ baboon/bibliography.html.)

Smuts, B. B. \& Smuts, R. W. 1993. Male-aggression and sexual coercion of females in nonhuman-primates and other mammals: evidence and theoretical implications. Advances in the Study of Behavior, 22, 1-63.

Soma, K. K. \& Wingfield, J. C. 2001. Dehydroepiandrosterone in songbird plasma: seasonal regulation and relationship to territorial aggression. General and Comparative Endocrinology, 123, 144155.

Stearns, S. C. 1992. The Evolution of Life Histories. Oxford: Oxford University Press.

Stephens, D. W. \& Krebs, J. R. 1986. Foraging Theory. Princeton, New Jersey: Princeton University Press.

Stevens, J. R. \& Stephens, D. W. 2002. Food sharing: a model of manipulation by harassment. Behavioral Ecology, 13, 393-400.

Stewart, D. R. M. \& Stewart, J. 1970. Food preference data by faecal analysis for African plains ungulates. Zoologica Africana, 5, 115-129.

Sugiyama, Y., Kawamoto, S., Takenaka, O., Kumazaki, K. \& Miwa, N. 1993. Paternity discrimination and intergroup relationships of chimpanzees at Bossou. Primates, 34, 545-552.

Susko, E., Inagaki, Y., Field, C., Holder, M. E. \& Roger, A. J. 2002. Testing for differences in rates-across-sites distributions in phylogenetic subtrees. Molecular Biology and Evolution, 19, 15141523.

Thornhill, R. 1983. Cryptic female choice and its implications in the scorpion fly Harpobatticus nigriceps. American Naturalist, 122, 765-788.

Tieszen, L. L. 1991. Natural variation in the carbon isotope values of plants: implications for archeology and paleoecology. Journal of Archaeological Science, 18, 227-248.

Tinbergen, N. 1951. The Study of Instinct. Oxford: Clarendon.

Tinbergen, N. 1972. Social Behaviour in Animals. London: Chapman $\&$ Hall.

Tong, J. 2002. Can it clock a nerf ball? New York Times, 13 November [Sect. 3:2].

van Schaik, C. P., van Noordwijk, M. A., van Bragt, T. \& Blankenstein, M. A. 1991. A pilot study of the social correlates of levels of urinary cortisol, prolactin and testosterone in wild long tailed macaques. Primates, 32, 345-356.

Vehrencamp, S. L. \& Bradbury, J. W. 1984. Mating systems and ecology. In: Behavioral Ecology. 2nd edn (Ed. by J. R. Krebs \& N. B. Davies), pp. 251-278. Sunderland, Massachusetts: Sinauer.
Vigilant, L., Hofreiter, M., Siedel, H. \& Boesch, C. 2001. Paternity and relatedness in wild chimpanzee communities. Proceedings of the National Academy of Sciences, U.S.A., 98, 12890-12895.

Wagner, S. S. \& Altmann, S. A. 1973. What time do the baboons come down from the trees? An estimation problem. Biometrics, 29, 623-625.

Wasser, S. K. (Ed.) 1983. Social Behavior of Female Vertebrates. New York: Academic Press.

Webb, J. N., Szekely, T., Houston, A. I. \& McNamara, J. M. 2002. A theoretical analysis of the energetic costs and consequences of parental care decisions. Philosophical Transactions of the Royal Society of London, Series B, 357, 331-340.

Weber, T. P., Houston, A. I. \& Ens, B. J. 1999. Consequences of habitat loss at migratory stopover sites: a theoretical investigation. Journal of Avian Biology, 30, 416-426.

West, M. J. \& King, A. P. 1988. Female visual displays affect the development of male song in the cowbird. Nature, 334, 244-246.

West, P. M. \& Packer, C. 2002. Sexual selection, temperature, and the lion's mane. Science, 297, 1339-1343.

West-Eberhard, M. J. 1992. Adaptation: current usages. In: Keywords in Evolutionary Biology (Ed. by E. F. Keller \& E. A. Lloyd), pp. 13-18. Cambridge, Massachusetts: Harvard University Press.

West-Eberhard, M. J. 2003. Developmental Plasticity and the Major Themes of Evolutionary Biology. Oxford: Oxford University Press.

Westneat, D. F. 1987. Extra-pair fertilizations in a predominantly monogamous bird: genetic evidence. Animal Behaviour, 35, 877886.

White, T. C. R. 1978. The importance of a relative shortage of food in animal ecology. Oecologia, 33, 71-86.

Whitten, P. L. \& Russell, E. 1996. Information content of sexual swellings and fecal steroids in sooty mangabeys (Cercocebus torquatus atys). American Journal of Primatology, 40, 67-82.

Whitten, P. L., Brockman, D. K. \& Stavisky, R. C. 1998. Recent advances in noninvasive techniques to monitor hormone-behavior interaction. Yearbook of Physical Anthropology, 41, 1-23.

Wikelski, M. C. 2002. www.princeton.edu/ wikelski/research/.

Wikelski, M. \& Cochran, W. W. In press. Individual migratory tactics of New World Catharus thrushes: current knowledge and future tracking options from space. In: Birds of Two Worlds (Ed. by P. Marra \& R. Greenberg). Washington, D.C.: Smithsonian Institution Press.

Williams, G. C. 1966. Adaptation and Natural Selection: a Critique of Some Current Evolutionary Thought. Princeton, New Jersey: Princeton University Press.

Wilson, E. O. 1971. The Insect Societies. Cambridge, Massachusetts: Belknap Press.

Wilson, P. L. \& Vehrencamp, S. L. 2001. A test of the deceptive mimicry hypothesis in song-sharing song sparrows. Animal Behaviour, 62, 1197-1205.

Wingfield, J. C., Lynn, S. E. \& Soma, K. K. 2001. Avoiding the 'costs' of testosterone: ecological bases of hormone-behavior interaction. Brain Behavior and Evolution, 57, 239-251.

Wold, H. 1956. Causal inferences from observational data: a review of ends and means. Journal of the Royal Statistical Society, Series A, $119,28-50$.

Woolfenden, G. E. \& Fitzpatrick, J. W. 1984. The Florida Scrub Jay: Demography of a Cooperative-breeding Bird. Princeton, New Jersey: Princeton University Press.

Ydenberg, R. C. \& Houston, A. I. 1986. Optimal tradeoffs between competing behavioral demands in the great tit. Animal Behaviour, 34, 1041-1050. 